\title{
Should managerial delegation contracts be made before or after union wage setting? A game-theoretic analysis ${ }^{\dagger}$
}

\author{
Nicola Meccheri ${ }^{\mathrm{a}, \mathrm{b},{ }^{*}}$ and Luciano Fanti ${ }^{\mathrm{a}}$ \\ ${ }^{a}$ Department of Economics and Management, University of Pisa, Pisa, Italy \\ ${ }^{\mathrm{b}}$ RCEA, The Rimini Centre for Economic Analysis, Rimini, Italy \\ Final version to be published on Managerial and Decision Economics
}

\begin{abstract}
:
This paper analyzes a multiple-stage game in which, at the final stage, two (managerial) firms compete over quantities in the product market. Prior to this stage, firm-specific unions set the workers' wages, while the owners of both firms hire managers and provide them with incentive contracts. Owners can freely decide to arrange the managerial contract before or after the (nonmanagerial) wage determination stage. Hence, the endogenous choice of the incentive contract stage is derived. The possibility of multiple equilibria arises, where both owners choose managerial contracts before or after unions' wage setting, crucially depending on unions' preferences. Such results also prove to be true for a remarkable degree of asymmetry in preferences over wages vis-àvis employment across unions.
\end{abstract}

Keywords: managerial delegation, unionized duopoly, endogenous sequence of contracts JEL codes: J51, L13, L21

\footnotetext{
${ }^{\dagger}$ We are extremely grateful to two anonymous referees for their comments and suggestions that have substantially improved the quality of the paper. We would like to thank also seminar participants at the Workshop "Oligopoly, Institutions and Firm Performance" (Pisa, 26-27 January 2017) and at the XV Workshop SIEPI (Palermo, 9-10 February 2017) for useful comments and suggestions. The usual disclaimers apply. This research is supported by the University of Pisa, project PRA 2016_02 "Oligopoly, institutions and firm performance".

${ }^{*}$ Corresponding author: Department of Economics and Management, University of Pisa, Via C. Ridolfi 10, I-56124 Pisa, Italy. E-mail: nicola.meccheri@,unipi.it
} 


\section{Introduction}

The interaction between managerial delegation, trade unions and imperfectly competitive product markets gives rise to many issues, which are relevant to the concerns of management strategy, industrial relations and labor economics, as well as industrial organization. Indeed, the presence of labor unions can change human resources management procedures related to hiring, compensation and benefits based upon their research and management's determination of business needs. A number of studies from different fields, ranging from human resource management to industrial relations, face those issues. In this paper, we adopt the approach of Industrial Organization (IO) to investigate a novel aspect of firms' strategic decisions in the presence of unionization and imperfect product market competition, namely how unions affect the optimal choice by firms' owners regarding the time for agreeing upon managerial contracts or, more specifically, if owners should strategically arrange those contracts before or after than unions set other (non-managerial) workers' wages.

To deal with that topic we will refer to two classic strands in the IO literature, namely managerial delegation and unionized oligopolies. ${ }^{1}$ Relatively recent contributions combine those theoretic frameworks to investigate how the interplay between labor unions and the choice of managerial delegation contracts affects firms' decisions and product market outcomes. Szymanski (1994) extends the standard managerial delegation model by introducing wage bargaining between managers and (firm-specific) unions, showing that owners set incentives closer to profit maximization than to sales maximization and that increasing union power may raise profitability of the firm. Bughin (1995), instead, considers a two-stage game in which, at the first stage, wages are bargained between firms and unions and, at the second stage, output decisions are made cooperatively by the owner (who maximizes profits) and the manager (who maximizes sales). In such a framework, it is highlighted that managerial incentive contracts weaken union power but, due to the presence of a prisoner's dilemma situation, unions are not averse to those contracts.

\footnotetext{
${ }^{1}$ Just to mention the seminal contributions, managerial delegation literature started with the pioneering works by Vickers (1985), Fershtman (1985), Fershtman and Judd (1987) and Sklivas (1987). Horn and Wolinsky (1988), Davidson (1989) and Dowrick (1989), instead, originated the literature on unionized oligopolies.
} 
Following Szymanski and Bughin's seminal works, Mauleon and Vannetelbosch (2006), Liao (2010, 2014), Fanti and Meccheri (2013, 2015), Meccheri and Fanti (2014), Chatterjee and Saha (2016) and Fanti (2016) study managerial-unionized oligopoly models to explore various issues, such as strategic delegation in wage bargaining and optimal managerial delegation contracts under alternative unionization regimes.

However, all the above-mentioned contributions share a common feature: by considering multiple-stage delegation games with unions, they assume that the sequence of moves is exogenously given. Generally speaking, the standard hypothesis is that firms' owners choose the managerial delegation contract at the first stage and wages for non-managerial workers are determined at the second stage, while at the final stage firms compete (i.e. managers choose strategic variables) in the product market. In some circumstances, such a sequence is a natural assumption. For instance, Szymanski (1994) considers that wages are bargained between managers and unions; in this case, "[a] natural (but not the only) interpretation of this set-up is that the manager bargains with the workforce collectively over the level of wages" (Szymanski 1994, p. 108). However, this sequence is no longer obvious when wages are bargained by firms' owners (Liao 2010, 2014) or, even less, under monopoly unions (Fanti and Meccheri 2013), that is, when unions directly fix wages. Hence, in the latter contexts, it makes sense to endogenize the stage at which firms' owners decide the incentive contract of their managers. In other words, there is room to explore the endogenous mechanisms governing the sequence of (managerial and union) contracts in the strategic delegation game between owners.

We investigate a multiple-stage game in which, at the final stage, two (managerial) firms compete over quantities in the product market. Prior to that, firm-specific unions set the workers' wages, while the owners of both firms hire a manager and delegate the output decision to this manager. The firms' owners also provide their managers with an incentive contract, that is, they choose a contract bonus weight to affect the manager's choice of output (sales). However, while the previous literature generally assumes that owners choose the incentive contract for their managers before wages are set by unions, we admit that owners can freely decide the "timing" of their choice. More specifically, they can choose to arrange the managerial contract before or after the (non- 
managerial) wage determination stage. ${ }^{2}$ Hence, we study the game between owners relative to the incentive contract stage in order to make this decision endogenous. This issue is highly relevant since final outcomes in product markets, particularly firms' profitability, can be greatly affected by the sequence of the contracts that endogenously arises in strategic contexts.

Our main results can be summarized as follows. When firms' owners adopt by assumption the same strategy (that is, they move together before or after unions' wage setting) as intuitive, they prefer to play a leader position with respect to their respective unions, that is, to choose managerial contracts before unions' wage setting. Instead, the results are much more elaborate and less intuitive when there is the possibility for owners to play asymmetric strategies. Indeed, in such a case, the opportunity for firms' owners arises to delay the arrangement of managerial contracts relative to the union wage determination stage. More exactly, the possibility of multiple equilibria in the sequence of contracts applies when unions are neither extremely oriented towards employment, nor sufficiently oriented towards wages. This depends on the interplay between incentives for owners to use managerial contracts in order to affect, on the one hand, competition in final product markets and, on the other, wage determination by unions. Indeed, since owners can dampen the union's wage claim by means of a negative bonus for the manager, when unions are distinctly oriented towards wages, it is better for owners choosing the managers' contracts before wage setting to contrast the stronger union's wage claim. Instead, when unions are employment-oriented, the (standard) "competition effect" on output played by the managerial bonus prevails. Owners prefer to provide incentives for sales, and profits are higher when the managerial contract is determined after wage setting, provided that the rival owner adopts the opposite strategy. Technically, in such a case, deviating from the (Pareto-dominant) equilibrium, in which both firms choose the managerial contract of their managers before unions' wage setting, is profit-enhancing and also leads to a multiple equilibria situation. Moreover, for a given range of the unions' preference parameter, the (less intuitive) equilibrium, in which owners "move" after their unions, is also risk-dominant and such results prove to be true also for a remarkable degree of asymmetry in preferences over wages vis-à-vis employment across unions.

\footnotetext{
${ }^{2}$ Consistently, the owners could decide to hire the manager (arranging at the same time the managerial contract) before or after unions' wage setting.
} 
To the best of our knowledge, the issue analyzed in this work is novel, since it has not been considered at all by the previous literature. ${ }^{3}$ However, it is worth recalling that, starting from the works by Gal-Or (1985), Dowrick (1986) and Hamilton and Slutsky (1990), a huge literature, also referred to as endogenous timing literature, does exist which deals with a somewhat related topic. It considers the strategic choice of timing between duopolists, that is, whether firms prefer making quantity or price decisions sequentially or simultaneously. Lambertini (2000a, 2000b) and Fanti (2016) introduce in such a framework the role of managerial incentive contracts and managerial delegation together with unionized labor market, respectively, maintaining the focus of the analysis on the timing of decisions made by firms about quantities or prices in the product market. Instead, Bárcena-Ruiz (2013) and, in a quite different framework, Bárcena-Ruiz and Espinosa (1996) consider the timing of incentive managerial contracts. In particular, Bárcena-Ruiz (2013) shows under price competition that, in a private duopoly, if one firm is the leader in incentive contracts the other firm prefers to be the follower. Hence, in equilibrium, firms' owners decide incentive contracts sequentially. By contrast, in a mixed duopoly, both the private and the public firm prefer to be the leader in incentive contracts. Thus, in equilibrium, firms make decisions simultaneously. Bárcena-Ruiz and Espinosa (1996), instead, study in a duopoly model with two stages of production whether firms' owners prefer to choose short-term contracts (i.e. incentive parameters are chosen in each of the two periods) or a long-term contract (i.e. incentive parameters for both periods are chosen at the beginning of the first period) for their managers. They show that under Cournot competition owners choose long-term incentive contracts and thus incentive parameters for the two periods are chosen simultaneously. Instead, under Bertrand competition one owner chooses a longterm contract and the other short-term contracts, meaning that owners choose managerial contracts simultaneously for the first period but sequentially for the second period.

\footnotetext{
${ }^{3}$ Kesavayuth and Zikos (2009) explore a partly related issue, that is, the endogenous determination of contracts in relation to the sequencing in the selection of R\&D and wages. However, this work differs from Kesavayuth and Zikos (2009) for various reasons. First, Kesavayuth and Zikos (2009) do not tackle managerial delegation. Moreover, while they aim at identifying under which conditions a particular contract type selection remains stable across firm-union pairs, this paper analyzes the decision by firms' owners on the timing of delegation contracts with respect to union wage setting.
} 
Clearly, even if the timing of strategic decisions is also a key concern of this work, it differs with respect to the above-discussed (endogenous timing) literature: the relevant strategic choice for firms' owners that is analyzed herein does not refer to one another moving simultaneously or sequentially but, instead, to choosing the incentive contracts of their managers before or after unions' wage setting, which is a completely different issue. Moreover, while Bárcena-Ruiz (2013) and Bárcena-Ruiz and Espinosa (1996) do not consider labor unions in determining wages, this is a key feature of our model, which plays a central role for our final outcomes.

The remaining part of the paper is organized as follows. In Section 2, we introduce the basic framework and briefly recall the results already derived in Fanti and Meccheri (2013) for the cases in which owners adopt symmetric strategies. We then study the case in which owners adopt asymmetric strategies. In Section 3, we endogenously derive the sub-game perfect equilibrium of the game between owners, showing that multiple equilibria can arise. Section 4 extends the model by introducing heterogeneity in unions' preferences into the analysis. Section 5 concludes, while more technical proofs are provided in the final Appendix.

\section{Model}

\subsection{Basic framework and sequence of the events}

This paper builds on Fanti and Meccheri (2013) where, motivated by their prominent institutional role in labor markets, we introduce the presence of unions in determining workers' wages in a managerial delegation basic framework (e.g. van Witteloostuijn et al. 2007; Jansen et al. 2009). In particular, we consider a normalized duopolistic Cournot market for a single homogeneous product, with inverse demand given by:

$$
p(Q)=1-Q
$$


where $p$ denotes price and $Q$ is the sum of the firms' output levels, $Q=q_{i}+q_{j}$, for $i, j=1,2$ and $i \neq$ $j^{4}$

Both firms produce according to a standard production function with constant returns to labor $q_{i}=L_{i}$, where $L_{i}$ represents the level of employment of firm $i$. Firm $i$ faces a marginal (and average) cost $0 \leq w_{i}<1$ for any unit of output produced, where $w_{i}$ is the per-worker wage. Therefore, firm $i$ 's cost function is linear and described by:

$$
C_{i}\left(q_{i}\right)=w_{i} L_{i}=w_{i} q_{i}
$$

We assume that wage contracts are monopolistically chosen by firm-specific unions, which have preferences weighted on wage and employment:

$$
V_{i}=w_{i}^{\theta} L_{i}^{1-\theta}=w_{i}^{\theta} q_{i}^{1-\theta}
$$

where $\theta \in(0,1)$ is the relative weight placed by unions on wages with respect to employment. In particular, $\theta>(<) 0.5$ means that unions have relatively more wage-oriented (employment-oriented) preferences, while $\theta=0.5$ refers to the special case of total wage-bill maximization. ${ }^{5}$

\footnotetext{
${ }^{4}$ Note that the standard inverse demand $p^{\prime}=a-b Q^{\prime}$ can be obtained from this normalized model simply by fixing $p=p^{\prime} / a$ and $Q=(b / a) Q^{\prime}$.

${ }^{5}$ In this section referred to the basic framework, we consider that the parameter $\theta$ is uniform across unions. This assumption will be relaxed in Section 4 where we will analyze the role played by heterogeneity of unions' preferences. Consider also that, with some caveats, $\theta$ could be interpreted as the relative bargaining power of the union in a Nash bargaining model where wages, instead of being monopolistically set by the union, are negotiated between the union and the firm. Indeed, denoting the relative bargaining power of the union by $\beta$, it is easy to show that the bargained wage $\left(w^{*}\right)$ increases monotonically in both $\theta$ and $\beta$, and that $\lim _{\theta \rightarrow 0} w^{*}=\lim _{\beta \rightarrow 0} w^{*}=0$. As pointed out by Lommerud and Straume (2012, fn. 13) "This is not surprising, as the two parameters will enter the Nash maximand in a mathematically similar way - and we might, in some applications, even choose the alternative interpretation of $\theta$ as reflecting the relative bargaining power of the trade union".
} 
Moreover, the owners of both firms hire a manager and delegate the output decision to this manager by means of a managerial contract. Such contract provides for a fixed salary to the manager plus a bonus element, which is related to a weighted combination between firms' profits and sales: if firm $i$ 's profits $\pi_{i}$ are positive - otherwise there is no bonus - manager $i$ receives a bonus that is proportional to $u_{i}=\pi_{i}+b_{i} q_{i}$, where the weight $b_{i}$ is chosen by owner $i$ to maximize profits and can be either positive or negative according to whether the owner provides incentives or disincentives to the manager's choice of output (sales). ${ }^{6}$
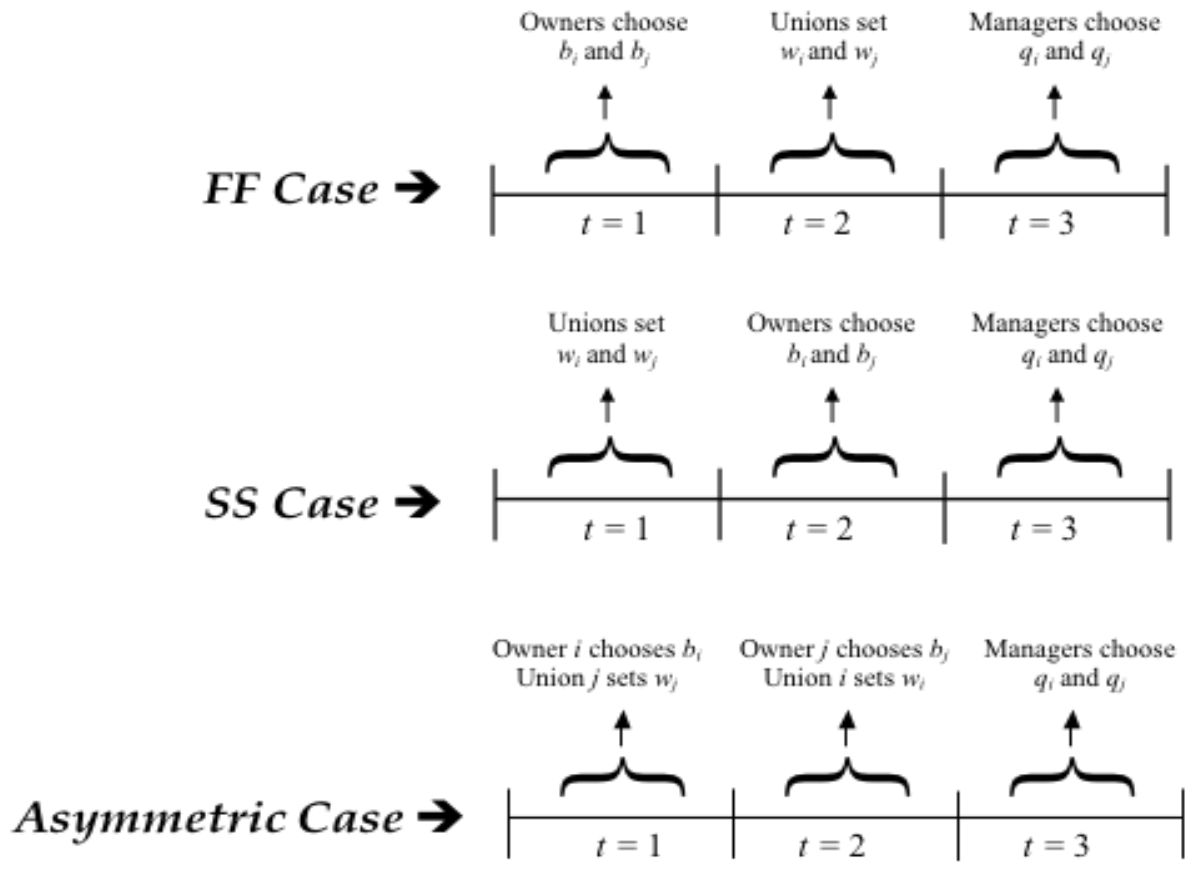

Figure 1. Sequence of events (possible sub-games)

We aim at investigating as the sequence of contracts (i.e. the managerial contract chosen by the firm's owner and the wage contract set by the union) endogenously arises. We consider that each firm's owner can decide to arrange the managerial contract before or after her/his union wage

\footnotetext{
${ }^{6}$ We also follow the standard assumption made by managerial delegation theory that the fixed component (salary) of the manager's pay is chosen by the firm's owner such that the manager exactly receives his/her opportunity cost, which is normalized to zero.
} 
setting. Accordingly, before the game begins (at a sort of pre-play stage), we admit that each owner $i$ can refer to three different possible sequence of events (or subgames) that will apply during the game, which are summarized in Figure 1. In particular, while we assume that, as usual (and natural), market competition always occurs at the final stage of the game $(t=3)$, with managers simultaneously choosing output, relative to the previous stages $(t=1$ and $t=2)$ three different scenarios are possible. In a first scenario (labeled as First-First or FF Case in Figure 1), both owners decide to arrange (simultaneously) managerial contracts at time $t=1$, that is, before their respective unions (simultaneously) set workers' wages (which occurs at $t=2$ ). In a second scenario (labeled as Second-Second or SS Case in Figure 1), both owners decide to arrange managerial contracts at time $t=2$, hence after union wage setting (which occurs previously at $t=1$ ). Finally, there is the possibility that an owner hires the manager and chooses the managerial contract at $t=1$ before her/his firm-specific union sets wages (at $t=2$ ), while the other owner chooses the opposite, which is the case labeled as Asymmetric Case in Figure 1.

Since the possible above-described sequences represent the core of this work, it is worthwhile providing and discussing a rationale behind them. Indeed, this can be done along different possible lines. First, in many multi-stage game theoretic models, the sequence of the moves is provided relative to the different degree of irreversibility or commitment of the decisions that should be made at different stages. The latter stages correspond to those decisions that are relatively easy to modify even in the short run, such as output or prices, while former stages relate to those that are "sunk" or that can be adjusted only in a longer time horizon, such as production capacity (Spence 1977; Dixit 1980) or R\&D investments (Brander and Spencer 1983). In this perspective, the possibility for firms' owners to choose managerial contracts before or after unions' wage setting may be linked to the different length of contracts. Specifically, we consider that owners are free to decide the length of managerial contracts relative to that of union contracts for non-managerial workers. Indeed, in many countries, collective agreements on employment involving trade unions are highly regulated by institutional norms and rules, which typically refer also to the duration of the agreement (i.e. the contract length). On the other hand, individual employment contracts, such as those for managers, are generally more flexible in any aspect, 
including duration, which can be defined by the parties. ${ }^{7}$ Accordingly, we can interpret our framework as follows: (institutionally) given the length of collective agreements, firms' owners can decide a duration for managerial contracts which is either shorter (which corresponds to a situation in which managerial contracts are chosen after wage contracts) or longer (which corresponds to a situation where managerial contracts are chosen before wage contracts) than that of union contracts. $^{8}$

Another possible interpretation hinges on the role of "agenda setters" that characterizes firms' owners in this framework, since they are centrally implicated in all relationships, with both managers and unions. Indeed, even if our theoretical model concentrates on a situation in which managerial contracts are chosen by firms' owners and workers' wages are set by unions, these can be considered special cases of bargaining between owners and managers over managerial contracts (with owners having all the bargaining power), and between owners and unions over wages (with unions having all the bargaining power), respectively. Consider, for instance, a situation in which there are two dates (which correspond to $t=1$ and $t=2$ of Figure 1), at which managerial contracts and wages should be decided (bargained). Since the owner is involved in both meetings (at least, $\mathrm{s} /$ he has to sign both contracts!), it makes sense to suppose that $\mathrm{s} /$ he retains the possibility to schedule the agenda, that is, to choose whether to meet the manager at time $t=1$ and the union at time $t=2$, or vice versa. ${ }^{9}$

\footnotetext{
${ }^{7}$ We defer to Malcomson (1999) for a broader discussion on this point and for further details about individual employment contracts.

${ }^{8}$ Note that such an interpretation also appears consistent with the idea of short-term and long-term managerial incentive contracts considered and analyzed, in a different framework (i.e. a dynamic two-period model where contracts can be either one or two periods long) and without unions, by Bárcena-Ruiz and Espinosa (1996). Indeed, as they affirm, "a long-term contract makes a firm a leader in incentives, while a short-term contract makes it a follower" (Bárcena-Ruiz and Espinosa 1996, p. 343).

${ }^{9}$ This can also provide a reason for ruling out a possibility that is not contemplated in our framework, namely managerial and wage contracts are offered simultaneously. Indeed, since we consider that the managerial contract is offered (chosen) by the firm's owner, while the wage contract is offered (set) by the union, excluding the possibility that managerial and wage contracts are determined simultaneously is quite reasonable. As pointed out by a referee, in a different context, such as the one where both contracts are
} 
According to the framework above discussed, and by adopting the usual backward induction logic, at the final stage (the market game), each manager sets the level of output for her/his firm to maximize $u_{i}=\pi_{i}+b_{i} q_{i}=\left(1-w_{i}-Q+b_{i}\right) q_{i}$, leading to the following reaction function in output space:

$$
q_{i}\left(q_{j}\right)=\frac{1-w_{i}-q_{j}+b_{i}}{2}
$$

From equation [4], by substituting for the corresponding of firm $j$, we get the equilibrium output, for given $w_{i}, w_{j}, b_{i}$ and $b_{j}$ (i.e. at the final stage):

$$
q_{i}\left(b_{i}, b_{j}, w_{i}, w_{j}\right)=\frac{1+2 b_{i}-b_{j}-2 w_{i}+w_{j}}{3} .
$$

However, before firms (managers) engage in competition, workers' wages should be set by unions and managerial contracts be defined by firms' owners. Since, we are interested in endogenously deriving the owners' choice of whether to define their managers' contracts before or after unions' wage setting, we first have to calculate and compare the (equilibrium) profits for firms' owners in relation to any pair of possible strategies, as represented in Figure 1: both owner $i$ and owner $j$ choose their managerial contracts before unions' wage setting (First-First case); both owner $i$ and owner $j$ choose their managerial contracts after unions' wage setting (Second-Second case); owner $i(j)$ chooses before wage setting while owner $j(i)$ after wage setting (Asymmetric strategies case).

\subsection{Symmetric strategies: First-First and Second-Second cases}

In this section we present the results relative to situations in which both firms' owners adopt a symmetric strategy: i) both choose to define the managerial contract before unions fix wages, and ii)

offered by the firm's owner(s), also the case in which contracts are offered simultaneously should be considered to endogenize the sequence of contracts. 
both choose the contract after wage setting. In some sense, the former option corresponds to a situation in which firms' owners decide to play a "leader" (first-mover) position with regard to their respective unions, while in the latter case they opt for a "follower" (second-mover) position. Since such situations have already been studied in Fanti and Meccheri (2013), we single out here only the results which are relevant to the analysis below, deferring to our previous work for greater detail.

In particular, identifying with the superscript $F F$ the case in which both owners move before unions (First-First case), standard backward analysis leads, for each firm $i$ and $j$, to the following (sub-game perfect) equilibrium bonus weight, output, wage and profit, respectively (Fanti and Meccheri, 2013, Section 3.1):

$$
\begin{aligned}
& b^{F F}=-\frac{7 \theta^{2}-20 \theta+4}{2\left(2 \theta^{2}-\theta-10\right)} ; \quad q^{F F}=\frac{(1-\theta)(4-\theta)}{(5-2 \theta)(2+\theta)} ; \\
& w^{F F}=\frac{3 \theta(4-\theta)}{2(5-2 \theta)(2+\theta)} ; \quad \pi^{F F}=\frac{(1-\theta)(4-\theta)\left(4+10 \theta-5 \theta^{2}\right)}{2(5-2 \theta)^{2}(2+\theta)^{2}} .
\end{aligned}
$$

Also important to our following analyses and results is the fact that, unless unions are distinctly oriented towards employment (i.e. unless $\theta<0.2164$ ), it is optimal for owners to "penalize" sales, that is, to choose a managerial contract providing for a negative bonus weight (Fanti and Meccheri, 2013, Lemma 1). This result contrasts with the received literature on managerial delegation (without unions), according to which, when firms compete in quantities, owners provide incentive for sales $(b>0)$ in order to drive their managers to be more aggressive in the market and force the rival to reduce output (e.g. Fershtman and Judd 1987). This result can be explained by the fact that, in the presence of unions, when firms' owners choose managerial contracts before wage setting, they can dampen the unions' wage claims by driving their managers to reduce output, hence employment. This "wage effect" outweighs the standard "competition effect" highlighted by the received literature, resulting in a negative equilibrium bonus weight. ${ }^{10}$

\footnotetext{
${ }^{10}$ This holds true unless unions are extremely employment-oriented. Obviously, in that case, the wage effect becomes negligible (unions "naturally" opt for a low workers' pay to increase employment, hence there is no
} 
Instead, identifying with the superscript $S S$ the case in which both owners move after unions (Second-Second case), we get that, for each firm $i$ and $j$, the following bonus weight, output, wage and profit, respectively, apply in (sub-game perfect) equilibrium (Fanti and Meccheri, 2013, Section 5):

$$
\begin{aligned}
& b^{S S}=\frac{3(1-\theta)}{5(3-2 \theta)} ; \quad q^{S S}=\frac{6(1-\theta)}{5(3-2 \theta)} ; \\
& w^{S S}=\frac{\theta}{3-2 \theta} ; \quad \pi^{S S}=\frac{18(1-\theta)^{2}}{25(3-2 \theta)^{2}} .
\end{aligned}
$$

Relative to the bonus weight, the standard outcome that managers are always rewarded for sales now always applies. This makes sense. When unions move before owners, from the latter's viewpoint, the situation is exactly the same as in the standard managerial delegation game without unions, in which firms face exogenously given production costs. In other words, there is no gain for owners to choose a negative bonus weight to reduce wages simply because wages have already been fixed by unions. Hence, only the standard competitive effect applies and, in equilibrium, the bonus weight on sales is positive, implying that managers behave more aggressively in the product market. To conclude this section, we establish the following lemma relative to the comparison of owners' profits when they adopt symmetric strategies:

Lemma 1. When firms' owners adopt symmetric strategies, they always prefer to choose their managers' contracts before unions set wages.

Proof. See the final Appendix.

room for reducing wages further by relying on bonus weight) and the competition effect prevails, leading to a (standard) positive equilibrium bonus weight. 
While a formal proof is provided in the Appendix, Figure 2 below presents a graphical analysis of Lemma $1 .^{11}$

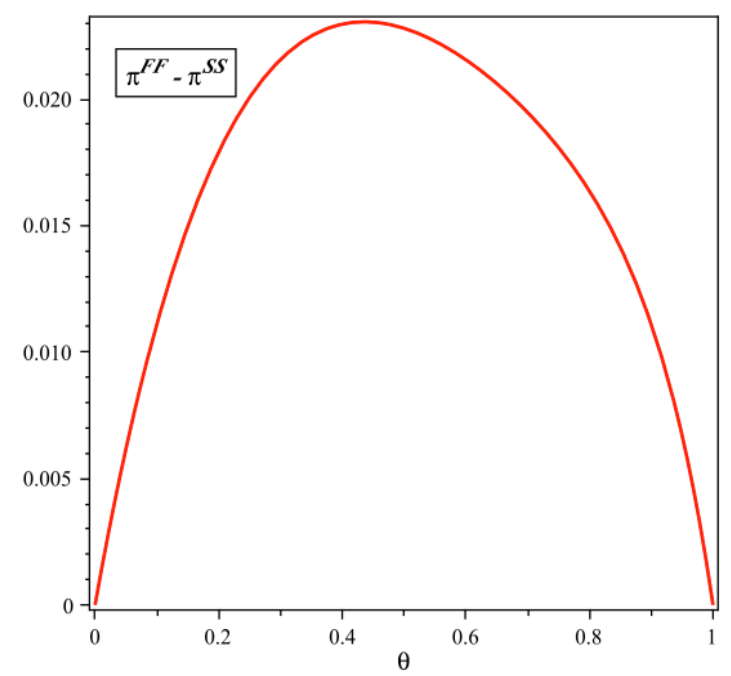

Figure 2. Symmetric strategies profit differential according to $\theta$

Intuitively, each owner (when the rival behaves in the same way) prefers to play a leader position with respect to the union that sets wages for her/his workers, since this permits the owner to obtain higher profits. Put in other words, from the firms' owners' viewpoint, the First-First pair of strategies, in which both owners choose the delegation contract of their managers before wage setting, always Pareto-dominates the Second-Second pair of strategies. This is because, by fixing a negative bonus weight in managerial contracts, owners encourage managers to reduce output (hence, employment) at the final stage, for any given wage level. In turn, this induces unions to put a brake on their wage claims to preserve an adequate level of employment.

Moreover, the greatest advantage for owners to choose managerial contracts before unions' wage setting realizes when unions are not excessively oriented either towards wages or towards employment (i.e. for intermediate values of $\theta$ ), hence they are willing to trade wage off for employment. Instead, when unions are only oriented towards employment $(\theta \rightarrow 0)$ or towards

\footnotetext{
${ }^{11}$ All graphical analyses are derived in MAPLE. More details and programs are available from the authors upon request.
} 
wages $(\theta \rightarrow 1)$, there is no advantage for firms' owners to assume a leader position with respect to their own unions, i.e. the profit differential $\pi_{F F}-\pi_{S S}$, represented in Figure 2, collapses to zero. Indeed, from [6] and [7], we can note that when $\theta \rightarrow 0$ wages do not depend on the bonus weights chosen by owners for their managers, eliminating the advantage for owners to "move" before union wage setting. Instead, when $\theta \rightarrow 1$ profits tend to zero in both $(F F$ and $S S)$ cases, ${ }^{12}$ hence also the differential $\pi_{F F}-\pi_{S S}$ will tend to zero.

\subsection{Asymmetric strategies}

To assess whether the (Pareto-dominant) First-First pair of strategies actually arises as equilibrium of the game between owners, we have to ascertain whether (or not) an owner gains by deviating from that strategy, hence evaluating the owners' profits when they play asymmetric strategies. ${ }^{13}$ For instance, without loss of generality, let us suppose that owner $i$ hires the manager and chooses the managerial contract before her/his firm-specific union sets wages, while owner $j$ plays the opposite strategy. Hence, just before managers compete in the product market, the union of firm $i$ has to fix the wage of its workers, taking $b_{i}$ and $w_{j}$ (that have already been determined) as well as $b_{j}$ as given. On the other side, owner $j$ has to choose the managerial contract, taking $b_{i}$ and $w_{j}$ (that have already been determined) as well as $w_{i}$ as given.

Substituting [5] in [3] and maximizing with respect to $w_{i}$, we get the sub-game perfect best-reply function in wages of union $i$ :

$$
w_{i}\left(b_{i}, b_{j}, w_{j}\right)=\frac{\theta\left(1+2 b_{i}-b_{j}+w_{j}\right)}{2} .
$$

\footnotetext{
12 This is due to the presence of the well-known "Chesire cat paradox".

${ }^{13}$ Since such a situation has not been considered before in the literature, we present and discuss the derivation of the equilibrium results for this case in greater detail.
} 
Instead, at the same stage, owner $j$ maximizes profits, $\pi_{j}=\left(p-w_{j}\right) q_{j}$, with respect to $b_{j}$, taking into account the corresponding (symmetric) equation of [5] for $q_{j}$, which leads to the following best-reply function for $b_{j}$ :

$b_{j}\left(b_{i}, w_{i}, w_{j}\right)=\frac{1-b_{i}+w_{i}-2 w_{j}}{4}$.

By substituting [9] in [8] and solving with respect to $w_{i}$, we get:

$$
w_{i}\left(b_{i}, w_{j}\right)=\frac{3 \theta\left(1+3 b_{i}+2 w_{j}\right)}{8+\theta}
$$

while, by substituting back in [9] for [10], and solving with respect to $b_{j}$, we obtain:

$$
b_{j}\left(b_{i}, w_{j}\right)=\frac{2\left(1-b_{i}-2 w_{j}\right)+\theta\left(1+2 b_{i}+w_{j}\right)}{8+\theta} .
$$

At the initial stage, by taking [10] and [11] into account, owner $i$ maximizes $\pi_{i}$ with respect to $b_{i}$, while union $j$ maximizes $V_{j}$ with respect to $w_{j}$, which leads to, respectively:

$$
\begin{aligned}
& b_{i}\left(w_{j}\right)=\frac{(4-13 \theta)\left(1+2 w_{j}\right)}{6(2+7 \theta)}, \\
& w_{j}\left(b_{i}\right)=\frac{\theta\left[2+\theta-2 b_{i}(1-\theta)\right]}{4-\theta} .
\end{aligned}
$$

Finally, by solving the system represented by [12] and [13], and then by substituting back, we get the following (sub-game perfect) equilibrium values for firm $i$ (the superscript $F S$ identifies the equilibrium values for the firm that moves before the union when the competitor behaves in the opposite way): 


$$
\begin{aligned}
& b^{F S}=\frac{(4-13 \theta)\left(4+3 \theta+2 \theta^{2}\right)}{2 A} ; \quad q^{F S}=\frac{3\left(4-\theta-\theta^{2}-2 \theta^{3}\right)}{A} ; \\
& w^{F S}=\frac{9 \theta\left(4+3 \theta+2 \theta^{2}\right)}{2 A} ; \quad \pi^{F S}=\frac{3\left(4-\theta-\theta^{2}-2 \theta^{3}\right)\left(8+34 \theta+25 \theta^{2}+14 \theta^{3}\right)}{2 A^{2}},
\end{aligned}
$$

where $A \equiv 24+86 \theta-55 \theta^{2}+26 \theta^{3}$. Instead, the following equilibrium values apply for firm $j$ (the superscript $S F$ identifies the equilibrium values for the firm that moves after the union when the competitor behaves in the opposite way):

$$
\begin{aligned}
& b^{S F}=\frac{4+27 \theta-39 \theta^{2}+8 \theta^{3}}{A} ; \quad q^{S F}=\frac{2\left(4+27 \theta-39 \theta^{2}+8 \theta^{3}\right)}{A} ; \\
& w^{S F}=\frac{\theta\left(8+65 \theta+8 \theta^{2}\right)}{A} ; \quad \pi^{S F}=\frac{2\left(4+27 \theta-39 \theta^{2}+8 \theta^{3}\right)^{2}}{A^{2}} .
\end{aligned}
$$

Proposition 1. Suppose that owner i decides his/her manager's contract before union's wage setting, while owner $j$ after union's wage setting. The following outcomes apply:

- the bonus weight set by owner $i$ is negative unless unions are distinctly oriented towards employment $(\theta<0.3077)$. Instead, the bonus weight set by owner $j$ is positive unless unions are distinctly oriented towards wages $(\theta>0.8355)$;

- this also leads to the following equilibrium output, wage and profit differentials between firms $i$ and $j$ :

$$
\begin{aligned}
& -\quad q_{i}<q_{j} \text {, unless } \theta<0.078 \\
& -\quad w_{i}<w_{j} \text {, unless } \theta<0.1949 ; \\
& \text { - } \quad \pi_{i}<\pi_{j} \text {, if } 0.0591<\theta<0.513 ; \pi_{i}>\pi_{j} \text {, otherwise. }
\end{aligned}
$$

Proof. See the final Appendix.

Proposition 1 points out that the results obtained and discussed in Section 2.2 are generally confirmed even when owners choose managerial contracts at different stages: a first-mover owner 
(with respect to the union but, in this asymmetric case, relative also to the rival owner) penalizes her/his manager on sales, while a second-mover provides her/his manager with incentives on sales. This applies, for instance, for the benchmark case of total wage bill maximizing unions (that is, when $\theta=1 / 2$ ). Indeed, only when $\theta$ is very high, that is, when unions are strongly wage-oriented, an owner (say owner $j$ ) who moves second also decides to penalize the manager on sales, which could seem quite counterintuitively. Specifically, since union $j$ has already set the wage when owner $j$ decides the managerial contract (hence, there is no possibility of dampening her/his own union's wage claims by hinging on the bonus weight of the manager), why should the latter choose a negative bonus?

The logic can be understood by considering that the negative bonus weight chosen (at the previous stage) by owner $i$ pushes, together with the high wage set (at the same stage) by the (strongly wage-oriented) union $i$, towards an increase in firm $j$ 's output. Thus, in order to moderate this output increase (which can also lead to an excessive market price reduction), owner $j$ has to penalize her/his manager on sales (output). In general, since owner $i(j)$ typically opts for a negative (positive) bonus, both output and wage are (generally) higher for firm $j$ than for firm $i$. In turn, since the market price is the same for both firms, this leads to a trade-off between revenues and production costs (wages).

Relative to profits, intuitively, when unions are distinctly wage-oriented, moving first is better to counter, by means of a negative bonus weight, the stronger wage claim made by the union. Instead, when unions are more (but not solely) employment-oriented, the effect on output prevails over that on wages, leading to a situation in which profits are higher for the firm that moves second. This is graphically shown in Figure 3. However, also note that profits are higher for owner $i$ (who moves first) when unions are only interested in employment, that is, when $\theta \rightarrow 0$. This makes sense. Indeed, in such a case, unions set wages at the workers' reservation level (which is zero in this model), corresponding to the situation in which marginal costs are exogenously given. Hence, this limiting case collapses de facto to the endogenous timing framework on whether firms' owners prefer to decide managerial contracts sequentially or simultaneously (Bárcena-Ruiz 2013) and, as 
expected, since competition is in output (strategic substitutes), both firms prefer to move before their rival, that is, to be the leader rather than to be the follower. ${ }^{14}$

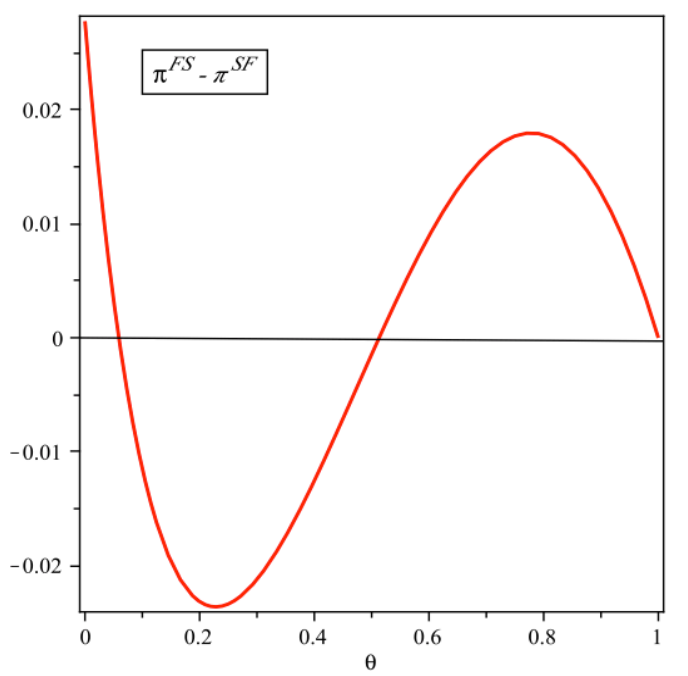

Figure 3. Asymmetric strategies profit differential according to $\theta$

\section{Equilibrium sequence of contracts}

In this section, we derive the equilibrium choice made by the firms' owners about the sequence of contracts, that is, whether to choose the delegation contracts for managers before or after their respective unions set wage contracts. The following table represents the strategic form of such a "moves game" between owners. Specifically, $F$ represents the strategy of moving first (i.e. choosing the delegation contract before wage setting), while $S$ that of moving second (i.e. choosing the delegation contract after wage setting).

\footnotetext{
${ }^{14}$ By contrast, when competition is in prices (strategic complements), the opposite applies (see Bárcena-Ruiz 2013, Section 3.2).
} 


\begin{tabular}{|c|c|c|}
\hline owner $i \backslash$ owner $j$ & $F$ & $S$ \\
\hline$F$ & $\pi^{F F}, \pi^{F F}$ & $\pi^{F S}, \pi^{S F}$ \\
\hline$S$ & $\pi^{S F}, \pi^{F S}$ & $\pi^{S S}, \pi^{S S}$ \\
\hline
\end{tabular}

Table 1: The owners' "moves game": strategic form

While Lemma 1 has already dealt with the comparison between $\pi^{F F}$ and $\pi^{S S}$, the following lemma deals with the comparisons of the pairs of profits, which are relevant to finding the equilibrium of the game in Table 1. As usual, this relates to the opportunity for a given firm to deviate from symmetric strategies (that is, $\pi^{F F} v S . \pi^{S F}$ and $\pi^{S S} v S . \pi^{F S}$ ).

Lemma 2. From simple comparisons of equilibrium profits under different strategies by firms', owners, the following results apply:

$$
\begin{array}{ll}
\text { - } & \pi^{F F}>\pi^{S F}, \text { for any } \theta \in(0,1) ; \\
\text { - } \quad & \pi^{S S}>\pi^{F S} \text { if } 0.018<\theta<0.47 ; \pi^{S S}<\pi^{F S} \text { otherwise. }
\end{array}
$$

Proof. See the final Appendix.

Figure 4 below provides a graphical proof of Lemma 2. 

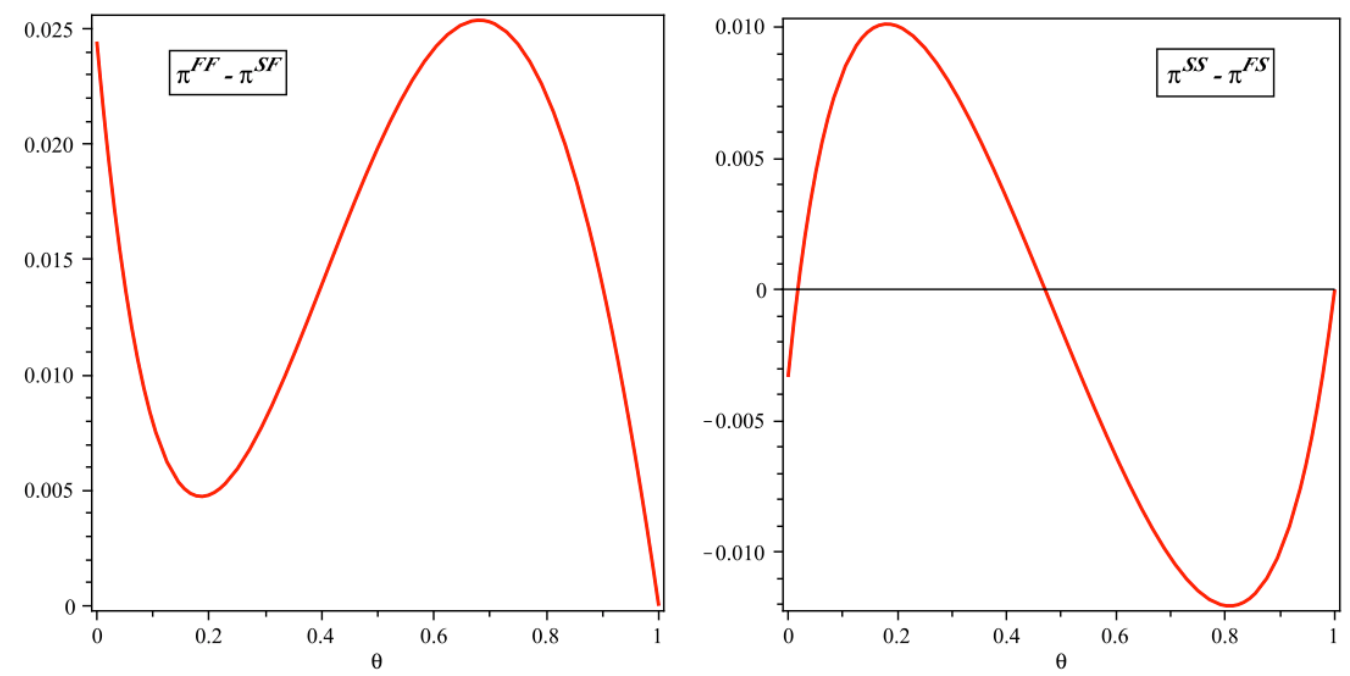

Figure 4. Incentives to deviate from symmetric strategies: profit differentials according to $\theta$ :

a) $\pi^{F F} v s . \pi^{S F}$ and b) $\pi^{S S} v s . \pi^{F S}$

The outcomes that arise from Lemma 2 are quite intuitive given what has already been discussed in Section 2 (especially relative to Proposition 1). Ideally, with respect to a pair of strategies providing that both owners move before their unions, there is no gain for an owner to deviate, since profits would be lower: when the competitor is also a leader, a firm's owner always prefers to be a leader than to be a follower of her/his own union. Instead, if both owners are followers of their unions, that is, they choose managerial contracts after unions' contracts, it is advantageous for an owner to deviate from this pair of strategies but only if the unions place a sufficiently large importance to wages, attaching to the latter at least the same weight than to employment. ${ }^{15}$ As discussed above, this result can be explained by the fact that, when unions are sufficiently wage-oriented (total wage-bill maximizing, at least), it is better to move first in order to dampen the union's wage claim. Instead, when unions are particularly (but not extremely) employment-oriented, on the one hand, the benefit of moderating the union's wage claim through a negative bonus is less sizable and, on the other, the standard "competition effect" becomes more important, especially because the rival owner, who moves at the later stage, will drive the manager

\footnotetext{
${ }^{15}$ To be rigorous, as stated by Lemma 2 and shown in Figure $4 \mathrm{~b}$ (right-hand side), this also applies in the less notable (and less interesting) case, in which unions are only interested in employment (i.e. $\theta<0.018$ ).
} 
to be more aggressive on the product market through incentives on sales. This implies that, in such a situation, it will be more advantageous to counter the competitor at the same (later) stage by choosing a higher positive bonus weight for the manager.

According to Lemma 2, and also taking Lemma 1 into account, the following proposition can now be established.

Proposition 2. When unions are neither extremely oriented towards employment, nor sufficiently oriented towards wages (that is, when $0.018<\theta<0.47$ ), the "moves game" between owners has two (Subgame Perfect) Nash equilibria, in which owners play symmetric strategies, i.e. First-First (FF) and Second-Second (SS). Such equilibria are Pareto-ranked: the equilibrium FF, in which both owners move before their respective unions, Pareto-dominates the equilibrium SS, in which both owners move after their respective unions. When, instead, unions are either extremely employment-oriented or, most importantly, sufficiently wage-oriented (total wage-bill maximizing, at least), the (Pareto-dominant) equilibrium FF only applies in the "moves game” between owners.

Proposition 2 reveals the possibility of multiple equilibria when $0.018<\theta<0.47$ and calls for further investigation for this case. Considering for the sake of simplicity and for reasons of stability only the pure-strategy equilibrium selection, ${ }^{16}$ we can refer to two most well known selection criteria: Pareto dominance and risk dominance. Indeed, one might argue that the Paretodominant equilibrium $F F$ is the focal point and owners would coordinate on such an equilibrium. However, as broadly supported by experimental results (e.g. van Huyck et al. 1990), agents frequently fail to coordinate on the Pareto-dominant equilibrium. In particular, coordination failure arises because of strategic uncertainty: if one player is uncertain that the other player will choose the efficient strategy, s/he might choose the safer option. Hence, when players are interested to minimize the risk of coordination failure, they will tend to coordinate on the risk-dominant strategy, even if it is Pareto-inferior with respect to another strategy.

\footnotetext{
${ }^{16}$ Since the game between owners when $0.018<\theta<0.47$ is a typical coordination game, in addition to the two pure-strategy equilibria there also exists one mixed-strategy equilibrium.
} 
Harsanyi and Selten's (1988) notion of risk dominance is known to capture this idea in twoagent games. Accordingly, a strategy pair risk-dominates another strategy pair if the product of the deviation losses is higher for the former. In this case of a symmetric game, if we assume that each owner assigns probabilities $1 / 2$ to each rival's strategy, ${ }^{17}$ then the strategic situation $F F$ (strictly) riskdominates $S S$ if the expected payoff from playing $F$ exceeds the expected payoff from playing $S$, that is, if $\left(\pi^{F F}+\pi^{F S}\right) / 2>\left(\pi^{S S}+\pi^{S F}\right) / 2$, or simply $\left(\pi^{F F}+\pi^{F S}\right)>\left(\pi^{S S}+\pi^{S F}\right)$. Obviously, when instead the opposite applies, $S S$ risk-dominates $F F$.

Proposition 3. There exists a range for $\theta$, which is given by $0.0973<\theta<0.2956$, according to which the strategic situation SS risk-dominates FF. Otherwise, the Pareto-dominant equilibrium FF is also risk-dominant with respect to $S S$.

\section{An extension: heterogeneous preferences across unions}

In this section, we extend the above analysis by admitting that preferences over wages and employment may differ across unions. Accordingly, unions' utility functions are now given by: ${ }^{18}$

$$
V_{i}=w_{i}^{\theta_{i}} q_{i}^{1-\theta_{i}}
$$

and standard analysis leads to the following equilibrium profits for any different case ( $F F$ case, $S S$ case and Asymmetric case): ${ }^{19}$

\footnotetext{
${ }^{17}$ The assignment of such probabilities can be considered an example of Bernoulli's Principle of Insufficient Reason.

${ }^{18}$ By comparing [16] against [3], notice that the index $i$ now also applies to the parameter $\theta$.

${ }^{19}$ For sake of space, analytical passages (which, however, parallel those above analyzed for the basic framework with homogeneous preferences across unions) are not reported here and are available from the authors upon request. In the final Appendix, sub-game perfect equilibrium values for wages, bonuses and output are reported for the different cases of this section.
} 


$$
\begin{aligned}
& \pi_{i}^{F F}=-\frac{\left(4-\theta_{j}\right)\left(4 \theta_{i} \theta_{j}-\theta_{i}-10 \theta_{j}-2\right)\left(1-\theta_{i}\right)\left[\begin{array}{l}
\theta_{i}^{2}\left(20 \theta_{j}^{2}-37 \theta_{j}+8\right)-2 \theta_{i}\left(29 \theta_{j}^{2}-28 \theta_{j}-10\right) \\
+4\left(5 \theta_{j}^{2}+11 \theta_{j}+2\right)
\end{array}\right]}{2\left[8\left(\theta_{i} \theta_{j}\right)^{2}-13 \theta_{i}^{2} \theta_{j}-13 \theta_{i} \theta_{j}^{2}-4 \theta_{i}^{2}-25 \theta_{i} \theta_{j}-4 \theta_{j}^{2}+56\left(\theta_{i}+\theta_{j}\right)+20\right]^{2}} \\
& \pi_{i}^{S S}=\frac{18\left(1-\theta_{i}\right)^{2}\left(2 \theta_{j}+3\right)^{2}}{25\left(9-4 \theta_{i} \theta_{j}\right)^{2}} ; \\
& \pi_{i}^{F S}=\frac{3\left(2 \theta_{i} \theta_{j}-\theta_{i}+4 \theta_{j}+4\right)^{2}\left(1-\theta_{i}\right)\left(7 \theta_{i}+2\right)}{2 A_{1}^{2}} ; \quad \pi_{j}^{S F}=\frac{2\left(4-\theta_{i}\right)^{2}\left(1-\theta_{j}\right)^{2}\left(8 \theta_{i}+1\right)^{2}}{A_{1}^{2}}
\end{aligned}
$$

where $A_{1} \equiv 26 \theta_{i}^{2} \theta_{j}-21 \theta_{i}^{2}-34 \theta_{i} \theta_{j}+78 \theta_{i}+8 \theta_{j}+24$ and, as above, the superscript $F F$ (resp. $S S$ ) indicates the profit of firm $i$ when both managerial contracts are chosen before (resp. after) wage setting, ${ }^{20}$ while $F S$ and $S F$ refer to the profits of firm $i$ and $j$, respectively, when the former chooses managerial contract before union wage setting and the latter adopts the opposite strategy.

Sub-game perfect equilibrium profits, reported in [17], can be used to endogenize the owners' choice about the timing of managerial contracts vis-à-vis union wage setting. The following table represents the strategic form of the game between owners when their unions (may) have asymmetric preferences over wages and employment:

\begin{tabular}{|c|c|c|}
\hline owner $i \backslash$ owner $j$ & $F$ & $S$ \\
\hline$F$ & $\pi_{i}^{F F}, \pi_{j}^{F F}$ & $\pi_{i}^{F S}, \pi_{j}^{S F}$ \\
\hline$S$ & $\pi_{i}^{S F}, \pi_{j}^{F S}$ & $\pi_{i}^{S S}, \pi_{j}^{S S}$ \\
\hline
\end{tabular}

Table 2: The owners' "moves game" with asymmetric unions: strategic form

\footnotetext{
${ }^{20}$ Notice that, since $i, j=1,2$ with $i \neq j$, firms' profits are now different even if they choose managerial contracts simultaneously.
} 
Similarly to what above done in the basic framework with homogeneous unions' preferences, we have to check the sign of the following key profit differentials in order to identify the firms' owners choice, hence the sequence of contracts that endogenously arises: $\pi_{i}^{F F} v S . \pi_{i}^{S F}$; $\pi_{i}^{F S} v s . \pi_{i}^{S S} ; \pi_{j}^{F F} v s . \pi_{j}^{S F}$ and $\pi_{j}^{F S} v s . \pi_{j}^{S S}$. While we get that $\pi_{i}^{F F}>\pi_{i}^{S F}$ and $\pi_{j}^{F F}>\pi_{j}^{S F}$ for any $\theta_{i}, \theta_{j}$ $\in(0,1)$, the sign of the other key profit differentials depends on parameters $\theta_{i}$ and $\theta_{j}$. The following figures show all the combinations of unions' preference parameters, for which $\pi_{i}^{S S}>\pi_{i}^{F S}$ (resp. $\pi_{j}^{S S}$ $>\pi_{i}^{F S}$ ) applies - in grey area X (resp. Y) -, or instead $\pi_{i}^{S S}<\pi_{i}^{F S}\left(\right.$ resp. $\left.\pi_{j}^{S S}<\pi_{j}^{F S}\right)$ holds true - in white area.
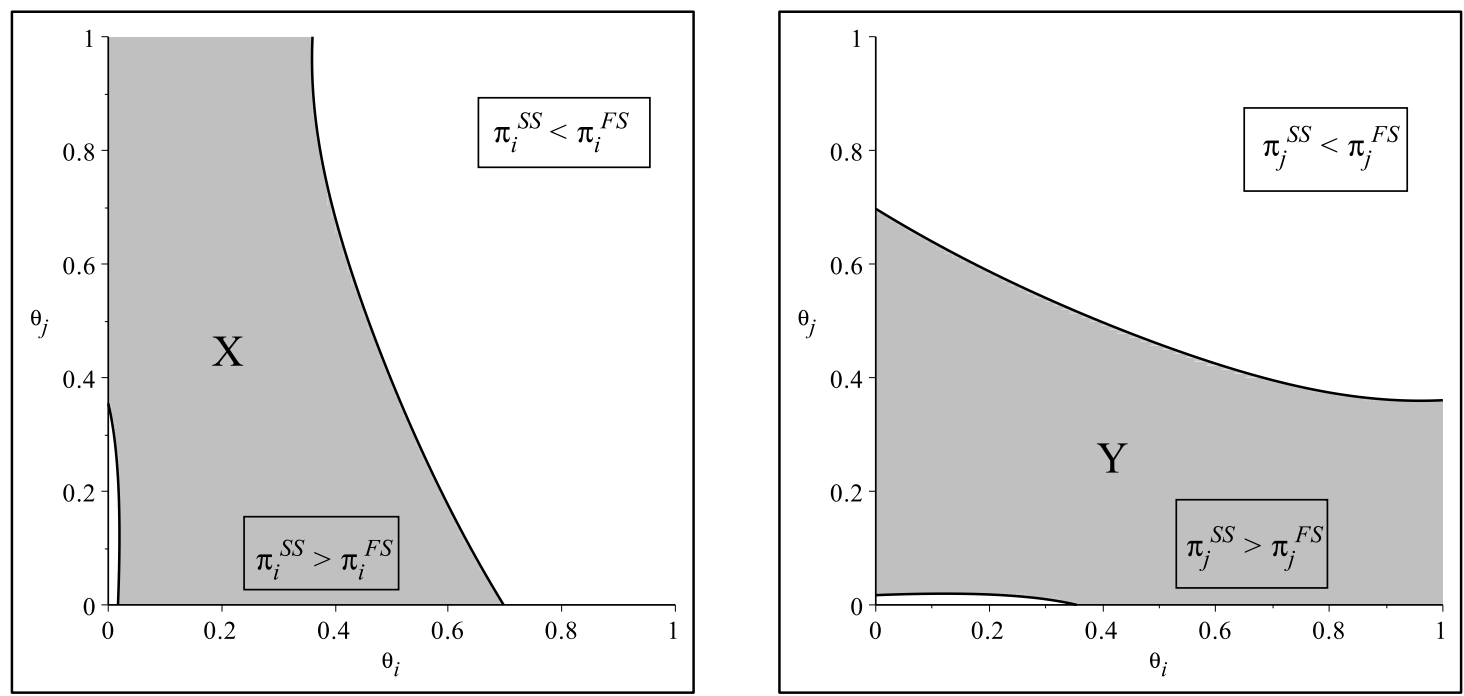

Figure 5. Incentives to deviate from symmetric strategies: a) $\pi_{i}^{S S} v s . \pi_{i}^{F S}$; and b) $\pi_{j}^{S S} v S . \pi_{j}^{F S}$

Hence, according to the results highlighted by the above figures, we can deduce that in the region where grey areas of Figure $5 \mathrm{a}$ and $5 \mathrm{~b}$ overlap, that is for all $\theta_{i}, \theta_{j} \in(0,1)$ for which $\langle\mathrm{X} \cap \mathrm{Y}\rangle$ applies, we get two symmetric sub-game perfect equilibria with owners choosing simultaneously managerial contracts before or after union wage setting. Instead, for all other combinations of $\theta_{i}$ and $\theta_{j}$ only one $F F$ equilibrium does exist, in which managerial contracts are chosen before union wage setting.

This result is represented by Figure 6, where the white area is characterized by the presence of only one $F F$ equilibrium while the dark area, obtained as intersection between areas $\mathrm{X}$ and $\mathrm{Y}$ of 
Figure 4, represents the region of multiple equilibria. Moreover, relative to the latter, in the darker blue area the $F F$ equilibrium risk-dominates the $S S$ equilibrium; instead, in the grey area located inside the multiple equilibria region, the $S S$ equilibrium is risk-dominant ${ }^{21}$ (also notice that in Figure 5 the 45-degree line permits to recall the homogeneous unions' preferences case of Section 3 , confirming the results discussed therein).

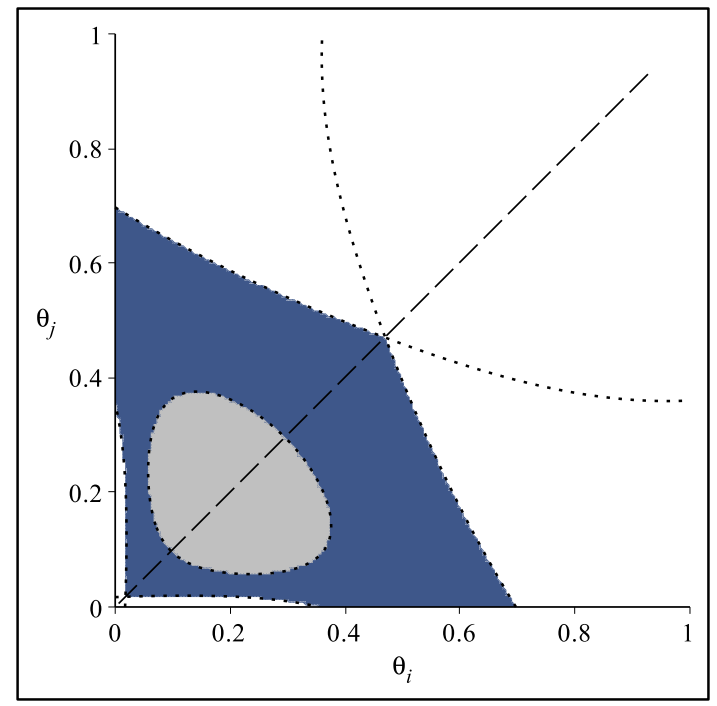

Figure 6. Endogenous equilibria with asymmetric unions

Note: white area: $F F$ equilibrium; blue area: $F F$ and $S S$ equilibria ( $F F$ riskdominant); grey area: $F F$ and $S S$ equilibria ( $S S$ risk-dominant)

Basically, the above-described results point out how introducing asymmetry in unions' preferences enable us to generalize the main results obtained in Section 3, which does not change qualitatively. At the same time, the analysis performed in this section permits to provide some interesting qualifications of the previous analysis. In particular, when unions are not particularly wage-oriented, multiple (symmetric) equilibria can be obtained for a remarkable degree of asymmetry in unions' preferences. For instance, from Figure 6, we can infer that when union $i$ is

${ }^{21}$ Since the game between owners is now asymmetric, due to the presence of heterogeneous preferences across unions, to analyze strategy risk-dominance we have to refer to the following inequality concerning products of deviation losses: $\left(\pi_{i}^{F S}-\pi_{i}^{S S}\right)\left(\pi_{j}^{F S}-\pi_{j}^{S S}\right) \geq\left(\pi_{i}^{S F}-\pi_{i}^{F F}\right)\left(\pi_{j}^{S F}-\pi_{j}^{F F}\right)$. 
total wage-bill maximizing, that is, $\theta_{i}=1 / 2$, multiple equilibria apply for any value of $\theta_{j}$ from 0 up to around 0.4 .

Finally, a finding of this section deserves to be recalled since it represents an interesting novelty with respect to the case analyzed in Section 3. Indeed, while with homogeneous unions' preferences an equilibrium can arise where both owners choose managerial contracts after union wage setting but, in that case, they both are worse off relative to the $F F$ case (that is, when the $S S$ equilibrium actually arises a prisoner's dilemma situation applies), introducing asymmetry in preferences can give rise to a situation in which, in the presence of multiple equilibria, an owner (but not both) is better off under $S S$ than under $F F$ equilibrium. This scenario is graphically represented in Figure 7, where the areas in blue (dark), which belong to the region where multiple equilibria apply, are those in which an owner (owner $i$ in area $\mathrm{H}$ or owner $j$ in area $\mathrm{K}$, respectively) is better off when both managerial contracts are chosen after union wage setting. ${ }^{22}$

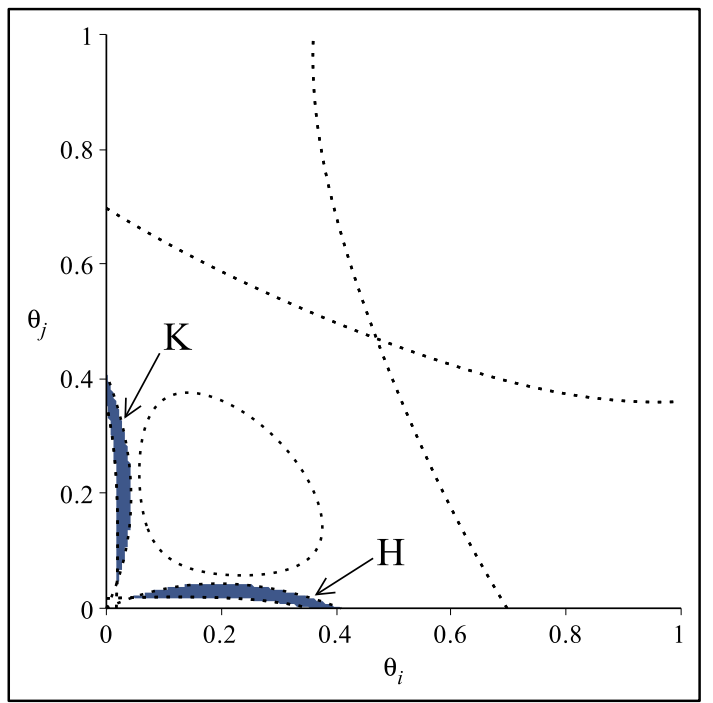

Figure 7. Areas $\mathrm{H}$ and $\mathrm{K}$ where an owner is better off under $S S$ equilibrium

\footnotetext{
${ }^{22}$ Notice, however, that in those areas the $S S$ equilibrium is not risk-dominant.
} 


\section{Conclusion}

In this paper we investigated a multiple-stage game in which, at the final stage, two (managerial) firms compete over quantities in the product market. Prior to that, firm-specific unions set the workers' wages, while the owners of both firms hire managers and provide them with incentive contracts in order to affect their output decisions in the product market. While the literature in question generally assumes that owners choose the incentive contract for their managers before wages are set by unions, we supposed that owners can freely decide the "timing" of their move, i.e. they can arrange the managerial contract before or after the (non-managerial) stage at which wage contract are determined. This can be rationalized by the fact that, while union contract length is institutionally defined, owners are free to decide the length of managerial contracts; alternatively, since owners are centrally implicated in all relationships with both their managers and unions, they play the role of "agenda setter" in this framework. Hence we analyzed the (endogenous) choice of the incentive contract stage, which is highly relevant to the concerns of industrial organization and corporate governance.

Due to the presence of strategic interaction at multi-stage levels (i.e. in product market competition, in unions' wage setting and in determining managerial incentive contracts), our findings show that, quite counter-intuitively, firms' owners may prefer not to play a leader position with respect to their own unions. To be more precise, there arises the possibility of multiple (subgame perfect) equilibria, where both owners choose managerial contracts before or after unions' wage setting (or contracts), when unions are neither extremely employment-oriented, nor sufficiently wage-oriented, hence crucially depending on unions' preferences. Moreover, for a given range of the unions' preference parameter, the (less intuitive) equilibrium, in which owners "move" after their unions, is also risk-dominant. Finally, admitting that unions have heterogeneous preferences over wages and employment permits to generalize the above findings, as well as to show that they hold true for a remarkable degree of asymmetry in unions' preferences.

Future research to extend our results could be carried out along various lines. The framework could be extended to deal with other managerial incentive structures, such as "relative 
performance delegation". Furthermore, assessing the robustness of our results by introducing, for instance, price competition and/or product differentiation into the analysis deserves to be explored.

\section{Appendix}

\section{A1 Proof of Lemma 1}

By comparing $\pi^{F F}$ from [6] against $\pi^{S S}$ from [7], we get:

$$
\pi^{F F}-\pi^{S S}=\frac{(1-\theta)\left(6180-13826 \theta+12465 \theta^{2}-4788 \theta^{3}+644 \theta^{4}\right)}{50(5-2 \theta)^{2}(2+\theta)^{2}(3-2 \theta)^{2}}>0, \forall \theta \in(0,1) .
$$

\section{A2 Proof of Proposition 1}

By taking $b^{F S}$ from [14] and $b^{S F}$ from [15], we get:

$$
\begin{aligned}
b^{F S} & \geq 0 \Leftrightarrow 4-13 \theta \underset{<}{<} 0 \Leftrightarrow \theta \frac{<}{>} \frac{4}{13}=0.3077 \\
b^{S F} & \geq 0 \Leftrightarrow 4+27-39 \theta+8 \theta^{2} \geq 0 \Leftrightarrow \theta \frac{\geq}{<} 0 \frac{39}{16}-\frac{3}{16} \sqrt{73}=0.8355 .
\end{aligned}
$$

Moreover, from [14] and [15], by comparing outputs, wages and profits under asymmetric strategies, we get (with $A \equiv 24+86 \theta-55 \theta^{2}+26 \theta^{3}$, as defined in the main text):

$$
\begin{aligned}
& q^{F S}-q^{S F}=\frac{4-57 \theta+75 \theta^{2}-22 \theta^{3}}{A} \frac{\geq}{<} 0 \Leftrightarrow 4-57 \theta+75 \theta^{2}-22 \theta^{3} \frac{\geq}{<} \Leftrightarrow \theta \frac{<}{>} \frac{53}{44}-\frac{3}{44} \sqrt{273}=0.078 ; \\
& w^{F S}-w^{S F}=\frac{\theta\left(20-103 \theta+2 \theta^{2}\right)}{A} \frac{\geq}{<} 0 \Leftrightarrow 20-103 \theta+2 \theta^{2} \frac{\geq}{<} \Leftrightarrow \theta \frac{<\frac{103}{4}-\frac{9}{4} \sqrt{129}=0.1949 ;}{>}
\end{aligned}
$$


$\pi^{F S}-\pi^{S F}=\frac{32-480 \theta-1494 \theta^{2}+8111 \theta^{3}-8133 \theta^{4}+2304 \theta^{5}-340 \theta^{6}}{2 A^{2}}<0 \Leftrightarrow 0.0591<\theta<0.513$.

\section{A3 Proof of Lemma 2}

By comparing $\pi^{F F}$ from [6] against $\pi^{S F}$ from [15] and $\pi^{S S}$ from [7] against $\pi^{F S}$ from [14], we get:

$$
\begin{gathered}
\pi^{F F}-\pi^{S F}=\frac{\left(\begin{array}{l}
2816-10112 \theta-60944 \theta^{2}+528832 \theta^{3}-766172 \theta^{4}+570016 \theta^{5} \\
-562742 \theta^{6}+467191 \theta^{7}-213449 \theta^{8}+48968 \theta^{9}-4404 \theta^{10}
\end{array}\right)}{2(5-2 \theta)^{2}(2+\theta)^{2} A^{2}}>0, \forall \theta \in(0,1) \\
\pi^{S S}-\pi^{F S}=\frac{3\left(\begin{array}{l}
-288-16512 \theta-12938 \theta^{2}-154277 \theta^{3}+356699 \theta^{4} \\
-328592 \theta^{5}+164516 \theta^{6}-52544 \theta^{7}+10912 \theta^{8}
\end{array}\right)}{50(3-2 \theta)^{2}}>0, \text { for } 0.018<\theta<0.47 .
\end{gathered}
$$

\section{A4 Equilibrium bonuses, wages and output with asymmetric unions}

FF case:

$$
\begin{aligned}
& b_{i}^{F F}=\frac{\left(2-4 \theta_{i} \theta_{j}+\theta_{i}+10 \theta_{j}\right)\left(7 \theta_{i} \theta_{j}-16 \theta_{i}-4 \theta_{j}+4\right)}{2\left[8\left(\theta_{i} \theta_{j}\right)^{2}-13 \theta_{i}^{2} \theta_{j}-13 \theta_{i} \theta_{j}^{2}-4 \theta_{i}^{2}-25 \theta_{i} \theta_{j}-4 \theta_{j}^{2}+56\left(\theta_{i}+\theta_{j}\right)+20\right]} \\
& w_{i}^{F F}=\frac{3 \theta_{i}\left(4-\theta_{j}\right)\left(2-4 \theta_{i} \theta_{j}+\theta_{i}+10 \theta_{j}\right)}{2\left[8\left(\theta_{i} \theta_{j}\right)^{2}-13 \theta_{i}^{2} \theta_{j}-13 \theta_{i} \theta_{j}^{2}-4 \theta_{i}^{2}-25 \theta_{i} \theta_{j}-4 \theta_{j}^{2}+56\left(\theta_{i}+\theta_{j}\right)+20\right]} \\
& q_{i}^{F F}=\frac{\left(4-\theta_{j}\right)\left(2-4 \theta_{i} \theta_{j}+\theta_{i}+10 \theta_{j}\right)\left(1-\theta_{i}\right)}{\left[8\left(\theta_{i} \theta_{j}\right)^{2}-13 \theta_{i}^{2} \theta_{j}-13 \theta_{i} \theta_{j}^{2}-4 \theta_{i}^{2}-25 \theta_{i} \theta_{j}-4 \theta_{j}^{2}+56\left(\theta_{i}+\theta_{j}\right)+20\right]}
\end{aligned}
$$


SS case:

$b_{i}^{S S}=\frac{3\left(1-\theta_{i}\right)\left(2 \theta_{j}+3\right)}{5\left(9-4 \theta_{i} \theta_{j}\right)} ; \quad w_{i}^{S S}=\frac{2 \theta_{j}+3 \theta_{i}}{9-4 \theta_{i} \theta_{j}} ; \quad q_{i}^{S S}=\frac{6\left(1-\theta_{i}\right)\left(2 \theta_{j}+3\right)}{5\left(4 \theta_{i} \theta_{j}-9\right)}$.

Asymmetric case:

$b_{i}^{F S}=\frac{\left(4-13 \theta_{i}\right)\left(2 \theta_{i} \theta_{j}-\theta_{i}+4 \theta_{j}+4\right)}{2\left(26 \theta_{i}^{2} \theta_{j}-21 \theta_{i}^{2}-34 \theta_{i} \theta_{j}+78 \theta_{i}+8 \theta_{j}+24\right)} ; \quad w_{i}^{F S}=\frac{9 \theta_{i}\left(2 \theta_{i} \theta_{j}-\theta_{i}+4 \theta_{j}+4\right)}{2\left(26 \theta_{i}^{2} \theta_{j}-21 \theta_{i}^{2}-34 \theta_{i} \theta_{j}+78 \theta_{i}+8 \theta_{j}+24\right)} ;$

$q_{i}^{F S}=\frac{3\left(1-\theta_{i}\right)\left(2 \theta_{i} \theta_{j}-\theta_{i}+4 \theta_{j}+4\right)}{26 \theta_{i}^{2} \theta_{j}-21 \theta_{i}^{2}-34 \theta_{i} \theta_{j}+78 \theta_{i}+8 \theta_{j}+24}$.

$b_{j}^{S F}=\frac{\left(4-\theta_{i}\right)\left(1-\theta_{j}\right)\left(8 \theta_{i}+1\right)}{26 \theta_{i}^{2} \theta_{j}-21 \theta_{i}^{2}-34 \theta_{i} \theta_{j}+78 \theta_{i}+8 \theta_{j}+24} ; \quad w_{j}^{S F}=\frac{\theta_{j}\left(8+\theta_{i}\right)\left(8 \theta_{i}+1\right)}{26 \theta_{i}^{2} \theta_{j}-21 \theta_{i}^{2}-34 \theta_{i} \theta_{j}+78 \theta_{i}+8 \theta_{j}+24}$

$q_{j}^{S F}=\frac{2\left(4-\theta_{i}\right)\left(1-\theta_{j}\right)\left(8 \theta_{i}+1\right)}{26 \theta_{i}^{2} \theta_{j}-21 \theta_{i}^{2}-34 \theta_{i} \theta_{j}+78 \theta_{i}+8 \theta_{j}+24}$

\section{References}

Bárcena-Ruiz J.C. (2013). Endogenous timing of incentive contracts in mixed markets under Bertrand competition, The Manchester School 81, 340-355.

Bárcena-Ruiz J.C. and Espinosa M.P. (1996). Long-term or short-term managerial incentive contracts. Journal of Economics and Management Strategy 5, 343-359.

Brander J.A. and Spencer B.J. (1983). Strategic commitment with R\&D: The symmetric case. Bell Journal of Economics 14, 225-235.

Bughin J. (1995). Unions and strategic managerial incentives. Economics Letters 47, 95-100.

Chatterjee I. and Saha B. (2016). Bilateral delegation in duopoly wage and employment bargaining. Managerial and Decision Economics (forthcoming - published online). 
Davidson C. (1988). Multiunit bargaining in oligopolistic industries. Journal of Labor Economics 6, 397-422.

Dixit A. (1980). The role of investment in entry deterrence. Economic Journal 90, 95-106.

Dowrick S. (1986). Von Stackelberg and Cournot duopoly: Choosing roles. RAND Journal of Economics 17, 251-260.

Dowrick S. (1989). Union-oligopoly bargaining. Economic Journal 99, 1123-1142.

Fanti L. (2016). An observable delay game with unionised managerial firms. Scottish Journal of Political Economy (forthcoming - published online).

Fanti L. and Meccheri N. (2013). Managerial delegation under alternative unionization structures. Labour 27, 38-57.

Fanti L. and Meccheri N. (2015). On the Cournot-Bertrand profit differential and the structure of unionisation in a managerial duopoly. Australian Economic Papers 54, 266-287.

Fershtman C. (1985). Managerial incentives as a strategic variable in duopolistic environment. International Journal of Industrial Organization 3, 245-253.

Fershtman C. and Judd K. (1987). Equilibrium incentives in oligopoly. American Economic Review 77, 927-940.

Gal-Or E. (1985). First mover and second mover advantages. International Economic Review 26, 649-653.

Hamilton J.H. and Slutsky S.M. (1990). Endogenous timing in duopoly games: Stackelberg or Cournot equilibria. Games and Economic Behaviour 2, 29-46.

Harsany J.C. and Selten R. (1988). A General Theory of Equilibrium Selection Games. MIT Press, Cambridge, MA.

Horn H. and Wolinsky A. (1988). Bilateral monopolies and incentives for merger. RAND Journal of Economics 19, 408-419.

Jansen T., van Lier A. and van Witteloostuijn A. (2009). On the impact of managerial bonus systems on firm profit and market competition: The cases of pure profit, sales, market share and relative profits compared. Managerial and Decision Economics 30, 141-153.

Kesavayuth D. and Zikos V. (2009). Endogenous contracts in unionized oligopoly. Labour 23, 209235.

Lambertini L. (2000a). Extended games played by managerial firms. Japanese Economic Review $51,274-283$. 
Lambertini L. (2000b). Strategic delegation and the shape of market competition. Scottish Journal of Political Economy 47, 550-570.

Liao P.-C. (2010). Strategic delegation under unionised duopoly: Who will bargain with unions? Australian Economic Papers 49, 276-288.

Liao P.-C. (2014). Strategic delegation of multiple tasks. Australian Economic Papers 53, 77-96.

Lommerud K.E. and Straume O.R. (2012). Employment protection versus flexicurity: On technology adoption in unionised firms. Scandinavian Journal of Economics 114, 177-199.

Malcomson J.M. (1999). Individual employment contracts. In Ashenfelter O. and Card D. (eds.) The Handbook of Labor Economics, Vol. 4. Amsterdam: North-Holland.

Mauleon A. and Vannetelbosch V.J. (2006). Strategic union delegation and incentives for merger. Applied Economics Letters 13: 1-5.

Meccheri N. and Fanti L. (2014). Managerial delegation contracts under centralized unionization. Managerial and Decision Economics 35, 51-66.

Sklivas S. (1987). The strategic choice of managerial incentives. RAND Journal of Economics 18, 452-458.

Spence A.M. (1977). Entry, capacity investment and oligopolistic pricing. Bell Journal of Economics 8, 534-544.

Szymanski S. (1994). Strategic delegation with endogenous costs. A duopoly with wage bargaining. International Journal of Industrial Organization 12, 105-116.

van Huyck J.B., Battalio R.C. and Beil R.O. (1990). Tacit coordination games, strategic uncertainty, and coordination failure. American Economic Review 80, 234-248.

van Witteloostuijn A., Jansen T. and van Lier A. (2007). Bargaining over managerial contracts in delegation games: Managerial power, contract disclosure and cartel behavior. Managerial and Decision Economics 28, 897-904.

Vickers J. (1985). Delegation and the theory of the firm. Economic Journal 95, 138-147. 